\title{
Review: antibiotics have a slight beneficial effect on acute bronchitis
}

Bent S, Saint S, Vittinghoff E, et al. Antibiotics in acute bronchitis: a meta-analysis. Am J Med 1999 Jul;107:62-7.

QUESTION: In patients with acute bronchitis, do antibiotics reduce sputum production, cough, or days off work?

\section{Data sources}

English language studies were identified in Medline (1966 to April 1998) by using the terms drug therapy, bronchitis, and acute disease; the reference lists of relevant articles were reviewed, and experts in the field were contacted.

\section{Study selection}

Studies were selected if they were randomised controlled trials that compared antibiotics with placebo in patients who had acute bronchitis but no history of chronic lung disease or pneumonia, therapy was given for $\geq 5$ days, and effect sizes could be calculated from the data presented.

\section{Data extraction}

Data were extracted on sample size, patient age, study inclusion and exclusion criteria, antibiotic regimen, and outcome measures. The main outcome measure was days of sputum production, which was transformed into units of standard deviation for each study.

\section{Main results}

8 studies (660 patients) were included and used erythromycin, doxycycline, or trimethoprim-sulfamethoxazole. The overall summary effect size of antibiotic therapy was 0.21 units of standard deviation (95\% CI 0.05 to 0.36 ), equivalent to about half a day less of cough and sputum production than with placebo. Days of purulent sputum, days of cough, and days lost from work were measured in $\geq 4$ trials; antibiotics and placebo did not differ (table).

Source of funding: no external funding.

For correspondence: Dr S Bent, General Internal Medicine

Section, San Francisco Veterans Affairs Medical Center 111A1, 4150 Clement Street,

San Francisco, $C A$ 94121, USA.

Fax +1415386

4044 .
Antibiotics v placebo for outcomes of acute bronchitis measured by $\geq 4$ trials

\begin{tabular}{lll} 
Outcomes & $\begin{array}{l}\text { Number } \\
\text { of trials }\end{array}$ & $\begin{array}{l}\text { Weighted mean } \\
\text { decrease }(95 \% \mathrm{CI})\end{array}$ \\
\hline Days of purulent sputum & 6 & $0.4 \mathrm{~d}(-0.1 \text { to } 0.8)^{*}$ \\
\hline Days of cough & 4 & $0.5 \mathrm{~d}(-0.1$ to 1.1$) \dagger$ \\
\hline Days off work & 6 & $0.3 \mathrm{~d}(-0.6$ to 1.1$) \dagger$ \\
\hline
\end{tabular}

*Significant when pooled in units of standard deviation, but not significant in units of days.

tHeterogeneity existed among these studies. Results were not significant.

\section{Conclusion}

In patients with acute bronchitis, the use of antibiotics reduces cough and sputum production by about half a day.

\section{COMMENTARY}

The systematic review by Bent and colleagues shows that antibiotics have marginal benefit in the treatment of adults with acute bronchitis. The results are consistent with those of 2 previous systematic reviews. ${ }^{12}$ Acute bronchitis is not a trivial illness; for most adults, it lasts $\geq 3$ weeks and has a major effect on patients' wellbeing and daily activities. ${ }^{3}$ This review suggests that antibiotics may shorten the duration of illness by half a day; but when side effects, costs of treatment, and the "medicalising" effects of antibiotics are considered, the risks associated with treatment seem to outweigh the benefits.

No symptoms or signs definitely rule in a bacterial diagnosis. It appears that patients' expectations substantially affect the prescribing of antibiotics by family physicians. ${ }^{4}$

In addition to evidence about the effectiveness of antibiotics, management strategies used to reduce prescribing and to meet patients' expectations are needed. A United Kingdom randomised trial is currently evaluating the effectiveness of offering each patient a delayed antibiotic prescription. Furthermore, a patient information leaflet has been shown to be effective for reducing repeated consultations and providing patients with information about the likely course of their illness.

Tom Fahey, MD University of Bristol Bristol, $U K$

1 Smucny JJ, Becker LA, Glazier RH, et al. Are antibiotics effective treatment for acute bronchitis? A meta-analysis. J Fam Pract 1998;47:453-60.

2 Fahey T, Stocks N, Thomas T. Quantitative systematic review of randomised controlled trials comparing antibiotic with placebo for acute cough in adults. BMJ 1998;316:906-10.

3 Verheij T, Hermans J, Kaptein A, et al. Acute bronchitis: course of symptoms and restrictions in patients' daily activities. Scand J Prim Health Care 1995;13:8-12.

4 Macfarlane J, Holmes W, Macfarlane R, et al. Influence of patients' expectations on antibiotic management of acute lower respiratory tract illness in general practice: questionnaire study. $B M J$ 1997;315:1211-14.

5 Macfarlane JT, Holmes WF, Macfarlane RM. Reducing reconsultations for acute lower respiratory tract illness with an information leaflet: a randomized controlled study of patients in primary care. Br J Gen Pract 1997;47:719-22. 